\title{
ANALYTICAL STUDIES OF THE IRON AND MANGANESE COMPLEXES OF 7-NITROSO -8- HYDROXYQUINOLINE -5- SULPHONIC ACID
}

\author{
E.O. Ojeka ${ }^{1}$ and J.F. Iyun ${ }^{2}$ \\ ${ }^{1}$ Department of Chemistry, Nasarawa State University, PMB 1022, Keffi, Nigeria \\ ${ }^{2}$ Department of Chemistry, Ahmadu Bello University, Zaria, Nigeria
}

\begin{abstract}
The ligand 7-nitroso-8-hydroxyquinoline-5-sulphonic acid $\left(\mathrm{H}_{2} L\right)$ possesses the coordination sites of 2 -nitroso-1- naphthol and of 8-hydroxyquinoline, where the hydroxyl group is functional at either site. The absorption maximum of the complex formed with iron and $M n$ is at 700nm, at which wavelength the mole extinction coefficient of $\mathrm{Fe}\left(\mathrm{H}_{2} \mathrm{~L}\right)_{3}$ is $27,540 \mathrm{dm}^{3} \mathrm{~mol}^{-1}$ and $\mathrm{Mn}\left(\mathrm{H}_{2} \mathrm{~L}\right)_{3}$ is 44,500 $\mathrm{dm}^{3} \mathrm{~mol}^{-1}$ respectively. The stoichiometry of $\mathrm{H}_{2} L$ reagent with the metal ions by the method of continuous variation gave the ratio of iron to ligand as 1:3 and manganese to Ligand as 1:3. Chemical analysis, and physicochemical evidence are compatible with formulating the Fe(II) and Mn (II) complexes as $\mathrm{H}\left[\mathrm{M}(\mathrm{HL})_{3}\right]$ where the 2-nitroso-1-naphthol site is involved in metal chelation.
\end{abstract}

Keywords: Analytical Studies, Iron, Manganese, Complexes, 7-nitroso -8, Hydroxyquinoline -5-

Sulphonic acid

\section{INTRODUCTION}

The ligand 7-nitroso-8-hydroxyquinoline-5sulphonic acid, denoted $\left(\mathrm{H}_{2} \mathrm{~L}\right)$ combines the characteristics of two of most reactive ligands, 2nitroso-1- naphthol and 8-hydroxyquinoline. The existence of two coordination sites in this ligand is interesting and complex formation with this ligand should occur through only one site (Eugene and Belford, 1964).

This ligand is represented structurally as:

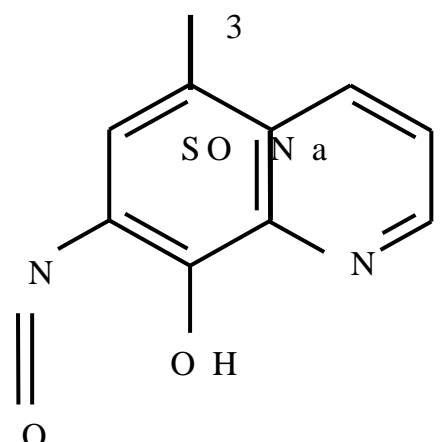


Nitrosonaphthols, 8-hydroxyquinoline and their sulphonated derivatives are known ligands, which react with metal ions to form neutral complexes with loss of a phenolic protion (Bajue et al., 1975).

$\mathrm{H}_{2} \mathrm{~L}$ ligand can be regarded as 2-substituted 8hydroxyquinoline in which the 2-substituent contains potential donor atom. The ligand possesses the additional feature that the quinoline ring system provides a completely rigid framework for the donor atom apart from combining the characteristics of two of the most reactive groups (Osmo and Niemi, 1972).

Nitrosonaphthol derivatives such as nitroso naphthols and sodium -1-1-nitroso-2-hydroxynaphthalene 3,6 disuphonates (nitroso-R-salts) are known to be selective and sensitive colorimetric reagents for cobalt and iron; while 2-nitroso-1naphthol forms chelate complexes with a number of metal ions such as $\mathrm{Cr}(\mathrm{II}), \mathrm{Cu}(\mathrm{II}), \mathrm{Fe}(\mathrm{III}), \mathrm{Ni}$ (III), Pd(II) and U(VI) (Toei and Motomizu, 1976; Sugii and Ogawa, 1979).

The reacting group of oxine comprises a phenolic hydroxyl and a basic nitrogen in position to form a five-membered ring; which ring chelates are more stable than the 6-membered rings due to steric hindrance by the benzene portion. Oxine reacts with at least 43 metals, which usually form hydroxides with ammonia (Stary, 1964).

Eldawy and Eishabouri (1975) applied this ligand $\left(\mathrm{H}_{2} \mathrm{~L}\right)$ with significant success, to the determination of iron (II) in multicomponent pharmaceutical preparation; without prior separation from other mineral ions, vitamins, and hormones which occur along with Fe (II) in geriatric preparation.

Ring nitrosation used in the ligand preparation is an electrophilic substitution reaction in which the attacking reagent is either the nitrosonium ion, $\mathrm{NO}$ or some species like $\mathrm{H}_{2} \mathrm{O}^{+}-\mathrm{NO}$ or NOCl that can easily transfer NO to the ring. Nitration ordinarily occurs only in rings bearing the powerfully activating dialkylamino $\left(-\mathrm{NR}_{2}\right)$ or hydroxyl $(\mathrm{OH})$ group (Morrison and Boyd, 1980).

\section{MATERIALS AND METHODS Experimental Apparatus}

Infrared spectra were obtained from hydrocarbon mulls utilizing, an ATI mattison Genesis FTIR colorimeter.

Unicam 8625 UV/VIS spectrometer and pye unicam 929 AA atomic spectrometer were used to determine the absorbance values recorded as well as to obtain the spectra presented. $\mathrm{pH}$ measurement were made with a philip PW 9408 pH meter with glass Calomel electrode.

The ${ }^{1} \mathrm{H}$ NMR spectra were scanned with a Varian mercury YH 200 spectrometer operating at 200 $\mathrm{MHz}$.

\section{Reagents and solutions}

All solutions were prepared with distilled water. Buffers were prepared in the usual manner using the appropriate salts as described elsewhere (James and Prichard (1974).

Manganese standard solution: $1.0 \mathrm{~g}$ of $99.8 \%$ manganese metal was dissolved in $10 \mathrm{ml}$ of redistilled $\mathrm{HNO}_{3}$ and diluted to $100 \mathrm{ml}$ with $1 \%$ (v/v) $\mathrm{HCl}$ such that $1 \mathrm{ml}=1 \mathrm{mg} \mathrm{Mn}$.

Triethanolamine Buffer ( $\mathrm{pH} 7-9$ ): 70ml of triethanolamine was dissolved in $60 \mathrm{ml}$ of water. Between $4-30 \mathrm{ml}$ of concentrated nitric acid were added to the solution to adjust the $\mathrm{pH}$ to the desired value and the volume was made up to 1 litre.

Standard iron solution: $0.01 \mathrm{~g}$ of pure iron was dissolved in $10 \mathrm{ml}$ of $\mathrm{HC} 1(1: 1)$ and $1 \mathrm{ml}$ of bromine water, and boiled to removed excess bromine. $200 \mathrm{ml}$ of $\mathrm{HCl}(1: 1)$ were added, cooled and diluted to 1litre in a volumetric flask with water.

0.10 percent 7-Nitroso-8-hydroxyquinoline-5sulphonic acid solution: $0.30 \mathrm{~g}$ of the reagent were dissolved in a mixture of ethanol and water (1:4) and then made up to $100 \mathrm{ml}$ in a calibrated flask. Residue was filtered off.

7-Nitroso-8-hydroxyquinoline-5- sulphonic Acid as a ligand and its metal complexes were prepared according to reported methods (Aly et al., 1973). 
Chelate combining ratio was established by a modified method of Diehl and Lindstrom (1959), in Table 3.

\section{pH and spectral studies}

The spectra of $\mathrm{H}_{2} \mathrm{~L}$ were run at wavelengths of 400, 500, 600 and 700nm respectively with $5 \mathrm{ml}$ of 0.5 percent of the reagent in acid medium of $\mathrm{pH} 3$ and alkaline medium of $\mathrm{pH} 8$; in Table I below.

Table 1: pH effect on Spectra

\begin{tabular}{ccc}
\hline $\begin{array}{c}\text { Wavelength of } \\
\text { measurement }(\mathbf{n m})\end{array}$ & $\mathbf{p H ~ 3}$ & $\mathbf{p H ~ 8}$ \\
\hline 700 & $0.001 \pm 0.00$ & $0.015 \pm 0.00$ \\
600 & $0.016 \pm 0.003$ & $0.018 \pm 0.00$ \\
500 & $0.050 \pm 0.00$ & $0.040 \pm 0.00$ \\
400 & $0.060 \pm 0.00$ & $0.058 \pm 0.01$ \\
\hline
\end{tabular}

Effect of acidity on Extraction

A solution containing $100 \mathrm{mg}$ of iron (III) metal ion was added to $5 \mathrm{ml}$ of 0.15 percent $\mathrm{H}_{2} \mathrm{~L}$ ligand in a stoppered separating funnel. The effect of interfering ions was circumvented by the addition of $3 \mathrm{ml}$ excess of the reagent. The solution was diluted with water to $25 \mathrm{ml}$ and made $0.20 \mathrm{M}$ in $\mathrm{H}_{2} \mathrm{SO} 4$; then extracted with two $10-\mathrm{ml}$ portions of butanol for $2 \mathrm{~min}$. The two extracts were combined in a $25 \mathrm{ml}$ flask and made to mark with nbutanol. The absorbance was read at 1 max of 700nm,( Table 2).
Table 2: The effect of acidity on extraction

\begin{tabular}{cc}
\hline Percent Extraction & Acidity (pH) \\
\hline 0 & 0 \\
98 & 1 \\
60 & 2 \\
36 & 3 \\
22 & 4 \\
\hline
\end{tabular}

Determination of the stoichiometry of 7-Nitroso-8 - Hydroxyquinolinol-5-Sulphonic Acid by the Method of Continuous Variation.

The variation of absorbance at a constant wavelength (lmax) of $700 \mathrm{~nm}$ was observed for a series of solution containing different volumetric ratio of metal - to ligand (reagent). A concentration of 0.1 $M$ of each metal was used and various volumes of $0.1 \mathrm{M}$ NHQS solution ranging from 0 to $2 \mathrm{ml}$ were added to the metal solution by means of a micrometer syringe. The optical densities of these solutions were measured at $700 \mathrm{~nm}$ against a similarly prepared reagent blank using the modified method of Diehl and Lindstrom (1959). The metal solutions were buffered with $2 \mathrm{ml}$ of Mcllvaine's citric acid - phosphate buffer at the start of the experiment.

\begin{abstract}
Absorption Spectra of Manganese (11) with variation in $\mathbf{~ p H}$

A $10 \mathrm{ml}$ portion of standard Mn (11) chloride $\left(\mathrm{MnC1}_{2} .4 \mathrm{H}_{2} \mathrm{O}\right)$ solution, $2 \mathrm{ml} .5$ percent hydroxylamine hydrochloride solution, $1 \mathrm{ml}$ complexing reagent solution and $2 \mathrm{ml}$ buffer were diluted to $50 \mathrm{ml}$ in a calibrated flask with distilled water.
\end{abstract}

Table 3: Stoichiometric studies of Fe(II) and Mn(II) with 7-nitroso-8- Hydroxyquinoline 5- Sulphonic Acid, by the method of continuous variation

\begin{tabular}{lccccccccc}
\hline $0.1 \mathrm{M}$ metal ion $(\mathrm{ml})$ & 0 & 0.2 & 0.4 & 0.5 & 0.6 & 0.8 & 1 & 1.2 & 1.4 \\
0.1M ligand solution (ml) & 1 & 1 & 1 & 1 & 1 & 1 & 1 & 1 & 1 \\
Buffer solution $(\mathrm{pH} 5)$ & 2 & 2 & 2 & 2 & 2 & 2 & 2 & 2 & 2 \\
Distilled water $(\mathrm{ml})$ & 2 & 1.8 & 1.6 & 1.5 & 1.4 & 1.2 & 1 & 0.8 & 0.6 \\
\hline
\end{tabular}


The absorbance of the solution was measured between $400-750 \mathrm{~nm}$ at various $\mathrm{pH}$ values against a reagent blank similarly prepared. The maximum absorbance occurred at 700nm and at $\mathrm{pH} 5 \pm 0.5$.

Table 4: Spectra of Manganese (11) with variation in $\mathbf{p H}$

\begin{tabular}{cc}
\hline $\mathbf{P H}$ & Absorbance at lmax (nm) \\
\hline 2 & 0.010 \\
4 & 0.013 \\
5 & 0.015 \\
6 & 0.014 \\
7 & 0.012 \\
8 & 0.010 \\
9 & 0.009 \\
10 & 0.006 \\
\hline
\end{tabular}

\section{RESULTS AND DISCUSSION}

Figure 1 shows the result of the spectrophotometric examination of $\mathrm{H}_{2} \mathrm{~L}$ reagent. It indicates a virtually identical spectra at $\mathrm{pH} 3$ and 8 respectively. This implies that this ligand can be used over a wide $\mathrm{pH}$ range for various determinations.

Figure 2 shows the degree or extraction of iron (III) with this ligand. The extraction falls at lower acidity probably due to the dissociation of a proton from the sulphonic acid group. At higher acidity, an extractable iron - ligand complex is formed. The formed species were highly hydrophilic due to the sulphonic acid group, and were rendered hydrophobic by the addition of $6 \mathrm{ml} \mathrm{n}$ butanol to enhance the percent extraction.

Figure 3 shows the effect of $\mathrm{pH}$ on Manganese ligand complex. Maximum absorption occurs at $480 \mathrm{~nm}$. The absorption at this wavelength rises to a maximum at about $\mathrm{pH} 8$ and decreases to almost zero after $520 \mathrm{~nm}$. The maximum absorption of the complex occurs at 700nm; thus the colour of the excess reagent has very little effect on the detection. The maximum peak height for $\mathrm{Mn}$ (II) was attained at $\mathrm{pH} 5.0$ being $\mathrm{pH}$ used for the experiment.
Stoichiometric studies were carried out using the modified method of Diehl and Lindstrom (1959). The amounts of reagents used in this work are indicated in Table 3. The predominant complexes formed are shown in figure 4 for manganese (II) as $\mathrm{PX}_{3}(1: 3)$ with $\epsilon$ value $44,500 \mathrm{dm}-\mathrm{mol}^{-1} \mathrm{~cm}^{-1}$ and figure 5 for Iron (II) as $\mathrm{PX}_{3}(1: 3)$ with $€$ value of $27,540 \mathrm{dm}^{3} \mathrm{~mol}^{-1} \mathrm{~cm}^{-1}$ respectively.

Figures 6 and 7 respectively show the infrared spectra of the disodium salt of the manganese and iron complexes with the $\mathrm{H}_{2} \mathrm{~L}$ ligand. The absence of a weak absorption in metal-ligand complexes (Figures 8 and 9), characteristics of nitroso group at $1400 \mathrm{~cm}^{-1}$ points to molecular interactions with these metal ions; while the $\mathrm{C}-\mathrm{C}$ bonds at about $1600 \mathrm{~cm}^{-1}$ may be due to tautomeric oxime group. The bands about 3368.74 to $3435.32 \mathrm{~cm}^{-1}$ are due to $\mathrm{O}-\mathrm{H}$ stretching frequency of the phenol group as well as nitroso, $\quad \mathrm{C}-\mathrm{N}, \mathrm{N}-\mathrm{O}, \mathrm{C}=\mathrm{O}, \mathrm{C}=\mathrm{N}$ and $\mathrm{NOH}$ groups.

The band around $1200 \mathrm{~cm}^{-1}$ appears to be aromatic band of sodium salt of sulphonic acid complex and that between700-800 $\mathrm{cm}^{-1}$ due to the suphuroxygen bond. This agrees well with findings by Bajue et al., (1975).

The intense visible band in $\mathrm{Na}_{2} \mathrm{FeL}$ may be due to charge transfer involving reduction of the iron (III) to iron (II) at $705 \mathrm{~nm}$ and similar charge transfer is feasible in $\mathrm{Na}_{2} \mathrm{MnL}$ complex in the UV/ visible spectra of nitrosonaphthols.

The sharp band at $910-895 \mathrm{~cm}^{-1}$ is probably due to $\mathrm{S}-\mathrm{O}$ stretching frequency in sulphonic acids while the coordinated metal-oxygen bonds are $\mathrm{Mn}-\mathrm{O}$ $\left(832.22-762.78 \mathrm{~cm}^{-1}\right)$ and $\mathrm{Fe}-\mathrm{O}\left(600.99-470.11 \mathrm{~cm}^{-}\right.$ $\left.{ }^{1}\right)$ respectively.

The ${ }^{1} \mathrm{H}$ NMR spectrum of NHQS in dimethylsuphoxide is presented in figure 6 with reference to tetramethyl silane (TMS). This assessment is made on the basis of earlier work by corsini and Louch (1974). The figure shows shifts of the $\mathrm{H}_{3}$ and $\mathrm{H}_{4}$ protons in the range 8.5- $8.7 \mathrm{ppm}$ which are influenced by substitutions in the phenolic ring. The $\mathrm{H}_{4}, \mathrm{H}_{6}$ and $\mathrm{H}_{8}$ and $\mathrm{H}_{2}+{ }_{3}+{ }_{4}+{ }_{6}$ protons 


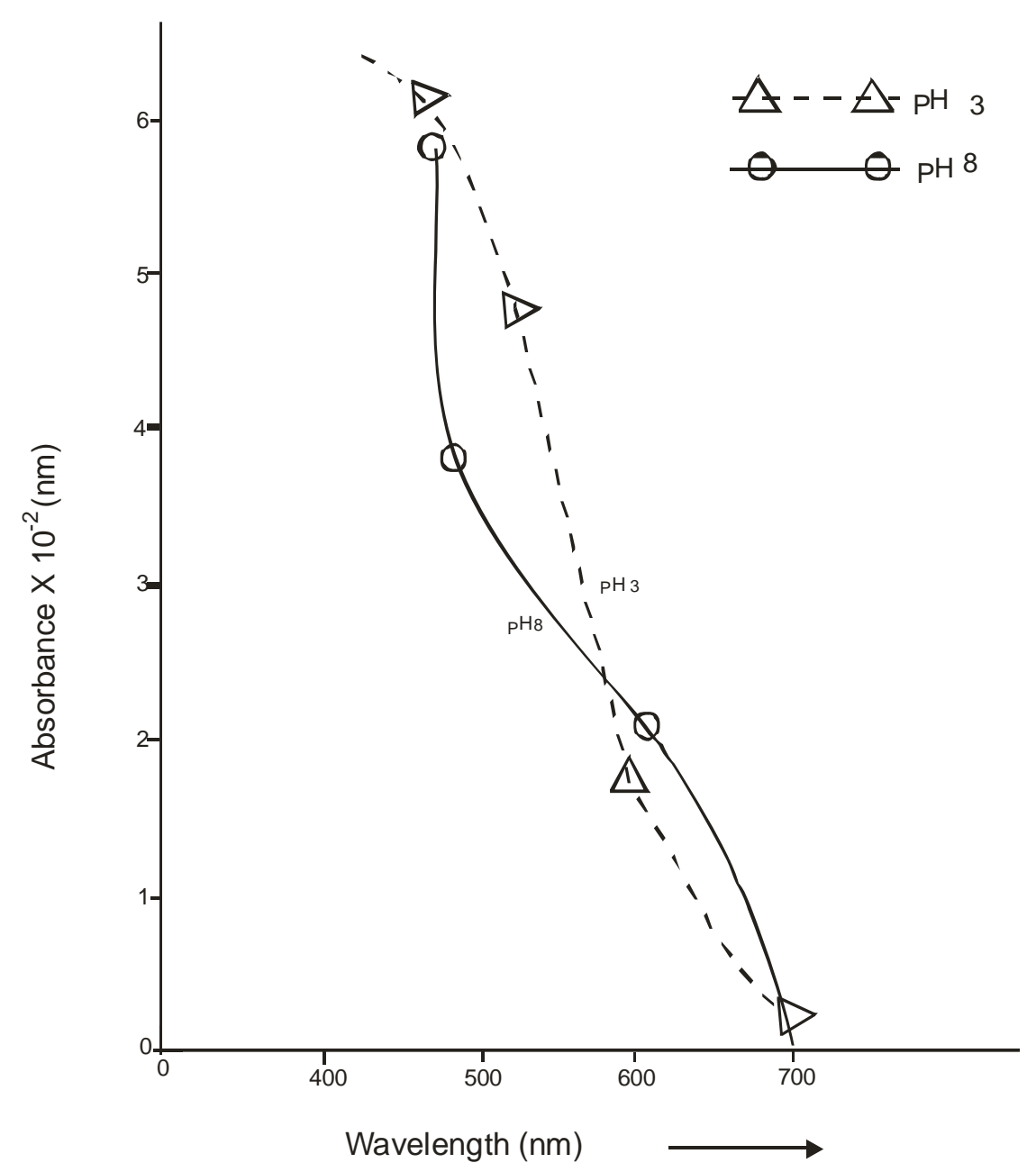

Fig. 1: pH Spectral curve for $5 \mathrm{ml} 1.5 \times 10^{-1}$ percent NHQS ligand in Acid and Base media 


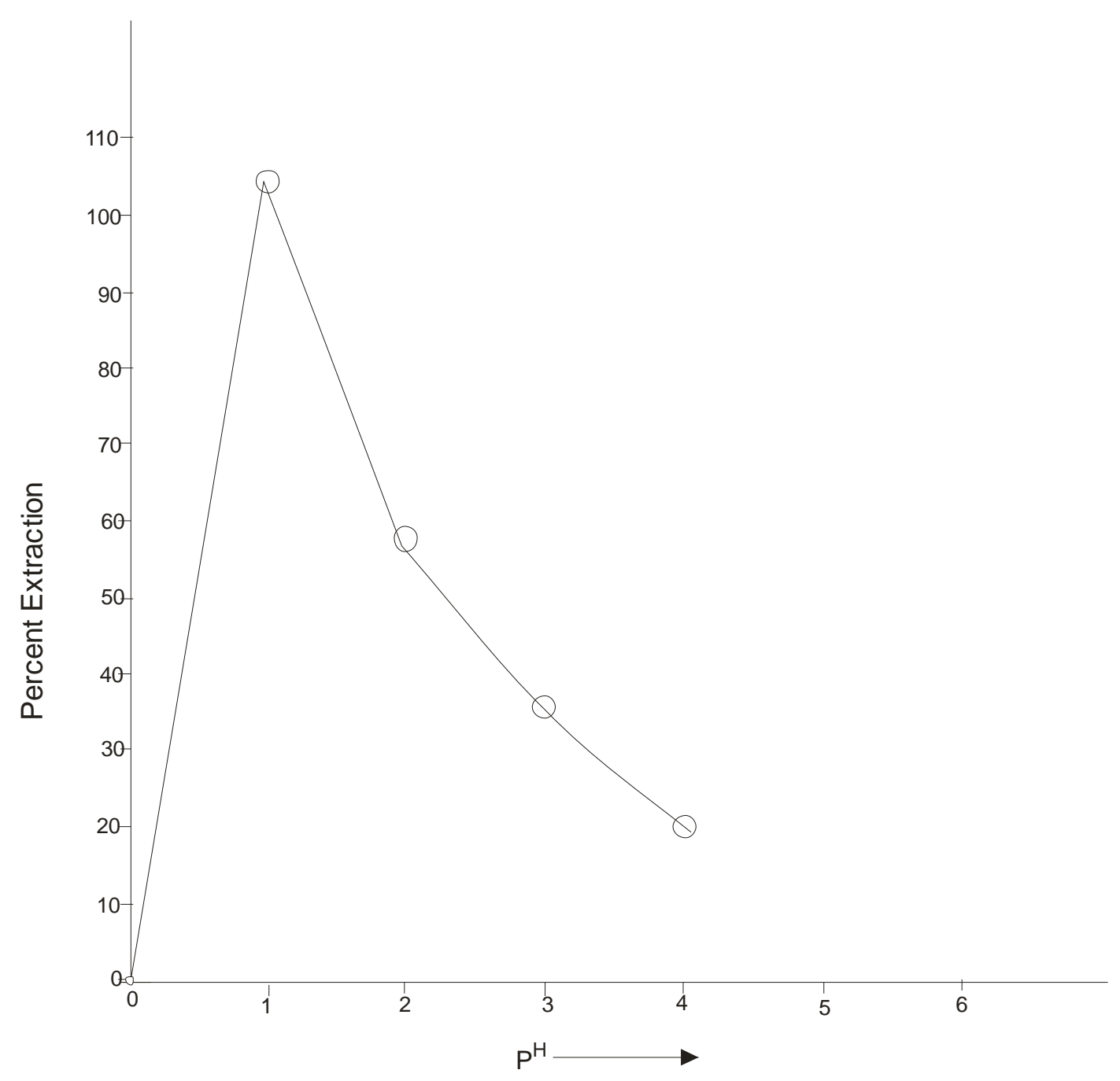

Fig. 2: The Effect of Acidity on percent Extraction of NHQS liqand

81 Journal of Science and Technology, Vol. 28, No. 1, April 2008 


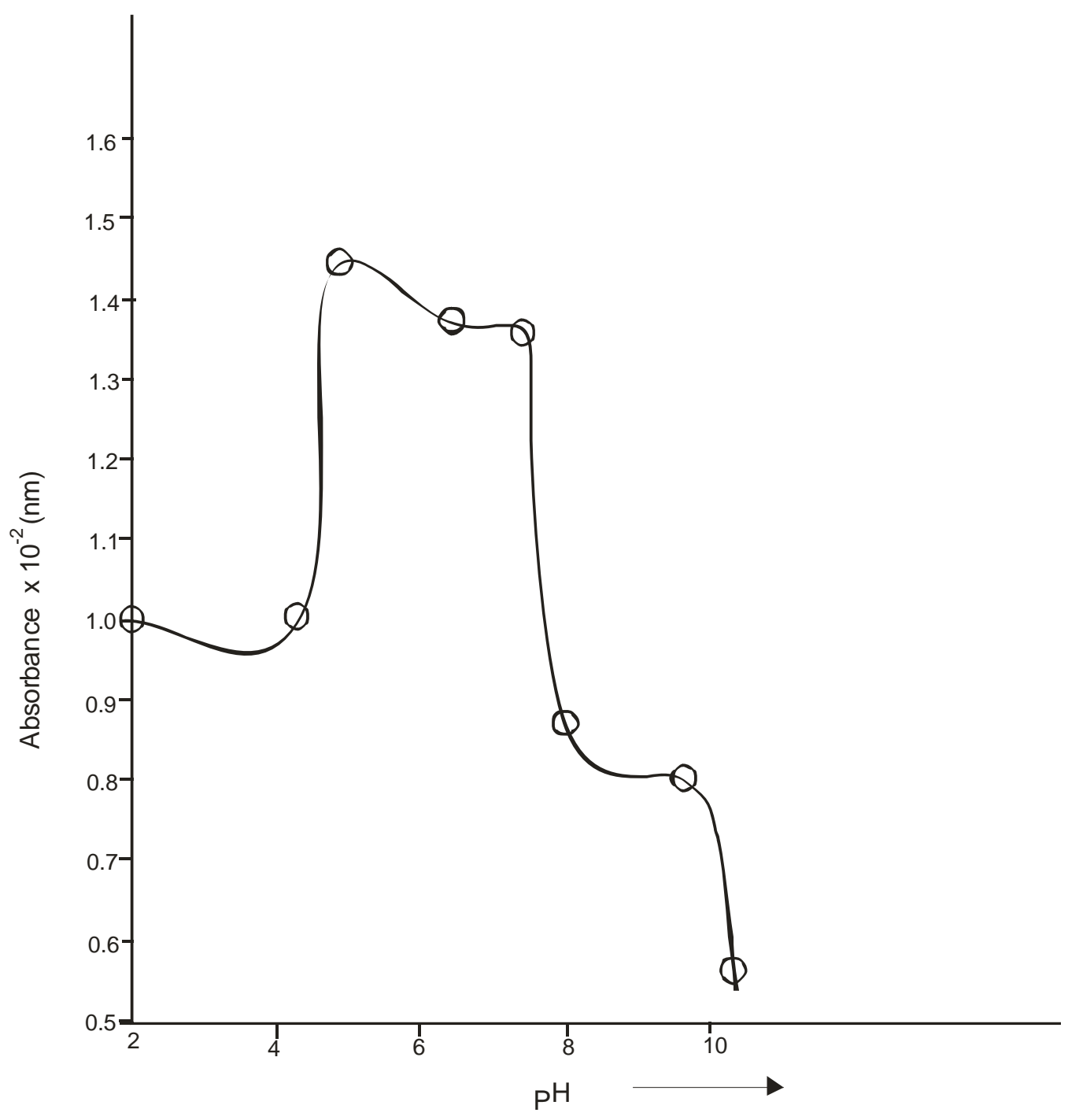

Fig. 3: Variation of Absorption spedra of Manganese (II) - NHQS Complex with variation in $\mathbf{p H}$ 


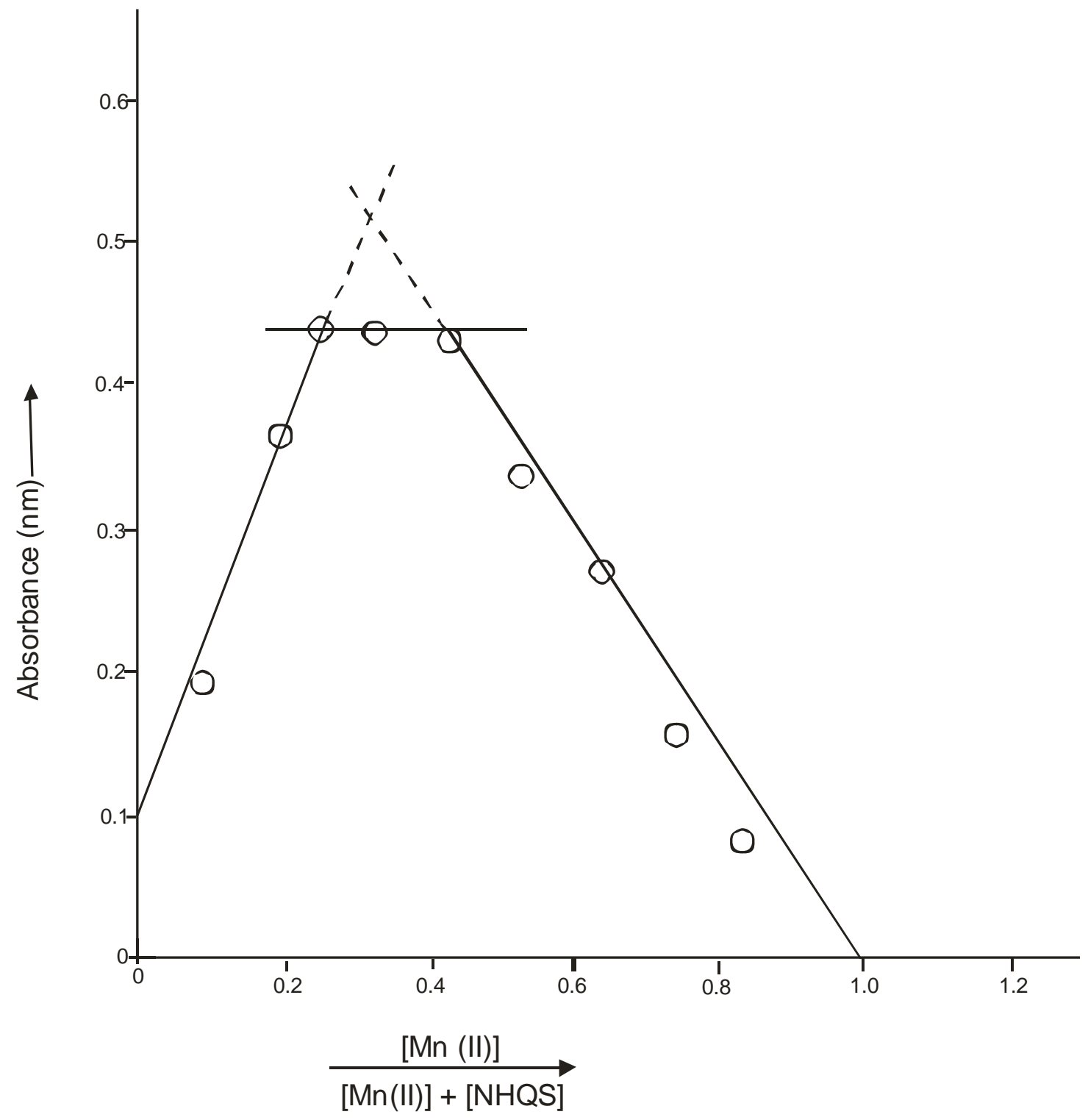

Fig. 4: Job's plot for Manganese - NHQS Complex

83 Journal of Science and Technology, Vol. 28, No. 1, April 2008 


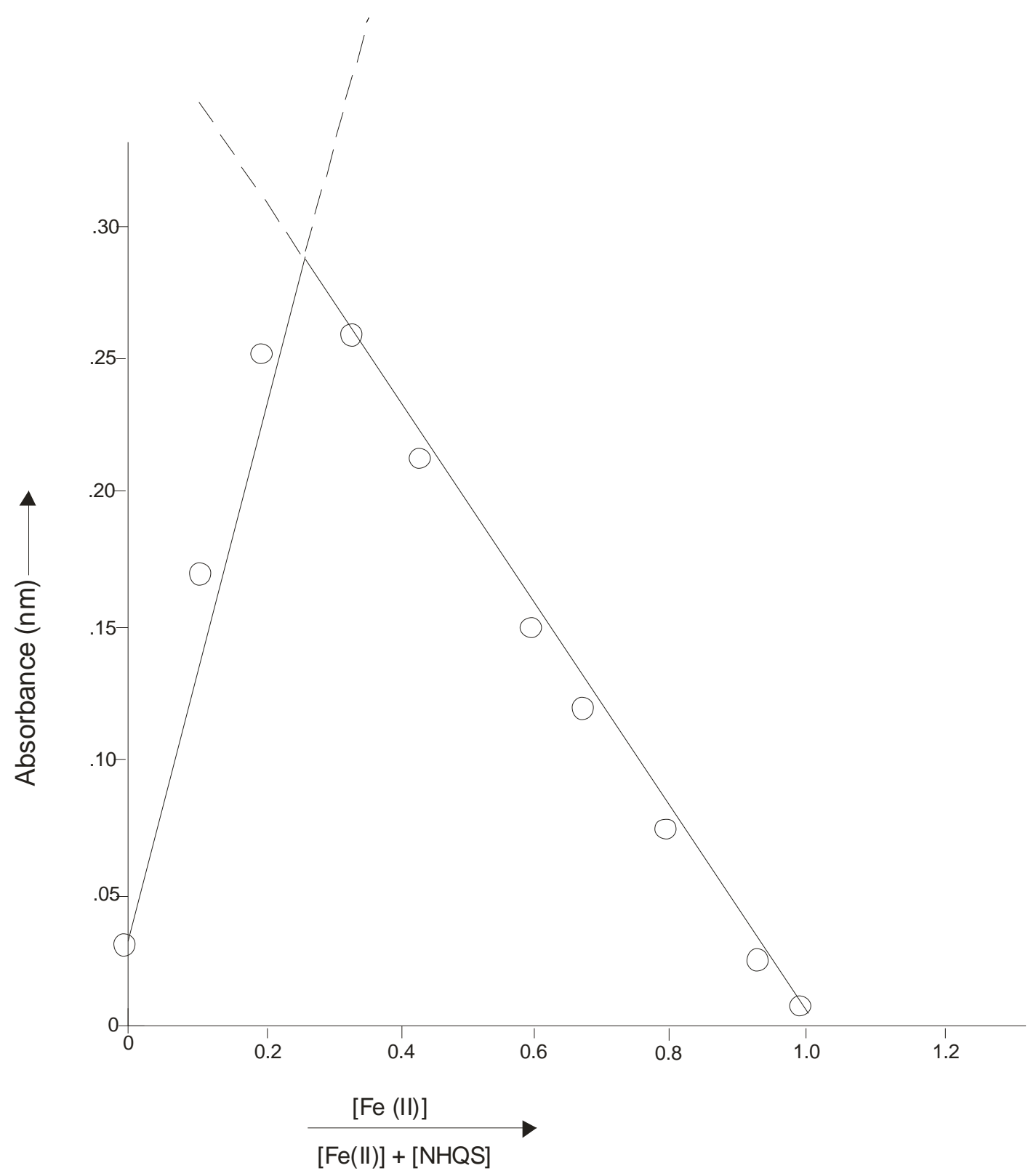

Fig. 5: Job's plot for Iron - NHQS complex 


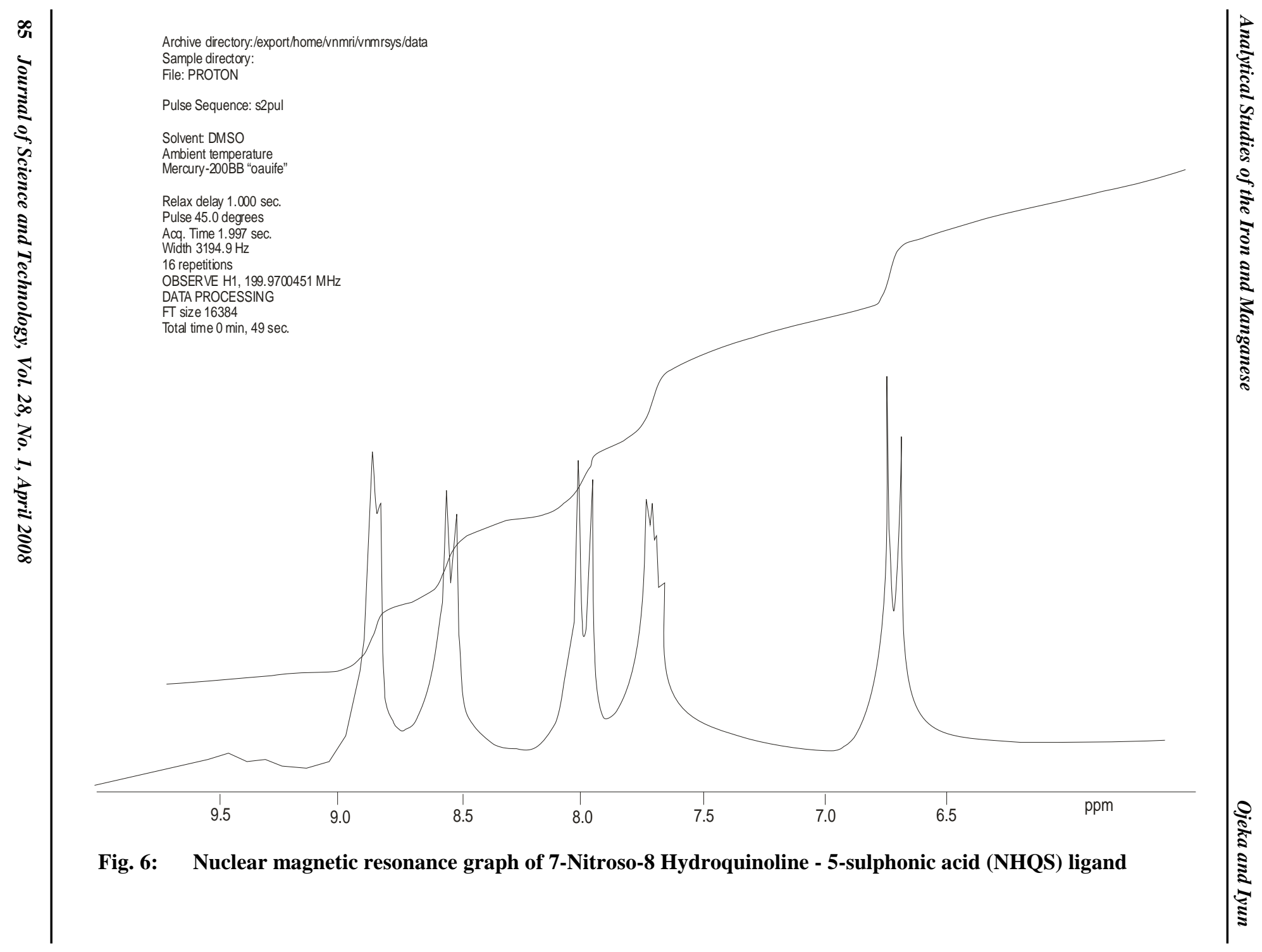


have chemical shifts in the range $7.6-7.90$. The proton ortho to an aromatic ring is deshielded and the greatest deshielding is exhibited by electron withdrawing groups in the 5 - position.

The nitroso form of the ligand tends to be dominant and bonds through the lone pair on the nitroso oxygen rather then nitroso nitrogen with little rotation about the $\mathrm{N}-\mathrm{C}$ bond of the nitroso group due to close proximity of ortho proton.

In the preliminary work, an attempted reaction of Iron (III) ion with the monosodium salt of the ligand produced a brown solution without precipitation. It is expected that the coordination of the third ligand molecule would result in the formation of Iron (II) complex. The resulting complex anion could attach a proton from the acidic medium, having an octahedral structure. This observation is consistent with that by Takashi et al; (1973) who reported that iron (II) formed a large monovalent complex anion with ntirosophenols and nitrosonaphthols as

$\mathrm{ML}_{\mathrm{n}}+\mathrm{HL}=\mathrm{ML}_{\mathrm{n}+1}+\mathrm{H}^{+}$

The binding of the nitroso group to these metal ions may take place either through the nitrogen or the oxygen atom (Eugene and Belford 1964). The shift of the $\mathrm{N}=0$ frequency according to Bellamy (1966) from $1530 \mathrm{~cm}^{-1}$ to higher frequency in the complexes is indicative of coordination involving the 2-nitroso-1-naphthol site. This trend was observed in figures 7-9 where 1613.70 increases to 1654.62 and $1842.33 \mathrm{~cm}^{-1}$ respectively; confirming the binding through the oxygen atom;

$$
\begin{aligned}
& 3 \mathrm{H}_{2} \mathrm{~L}+\mathrm{Fe}(\mathrm{II})+\mathrm{H}^{+}=\mathrm{H}\left[\mathrm{Fe}(\mathrm{HL})_{3}+3 \mathrm{H}^{+}\right. \\
& 3 \mathrm{H}_{2} \mathrm{~L}+\mathrm{Mn}(\mathrm{II})+\mathrm{H}^{+}=\mathrm{H}\left[\mathrm{Mn}(\mathrm{HL})_{3}\right]+3 \mathrm{H}^{+}
\end{aligned}
$$

\section{CONCLUSION}

From the evidence provided in this study, the binding of the nitroso group to iron and manganese is probably through the oxygen atom as shown in the structure below.
Suggested structure of NHQS - metal Bonding via Oxygen atoms:

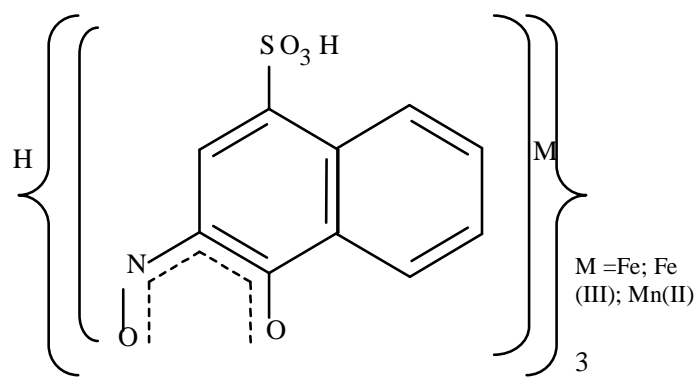

\section{REFERENCES}

Aly, M. M., El-ezaby, S. and Makhyoun, M. (1973). Coordination compounds of Ligands containing more than one coordination site. $J$. Inorg. Nucl. Chem. 35: 2727-2734.

Bajue, S. A., Lalor, G. C. and Stuart, K. L. (1975). The Reactions of Cobalt Compounds with Nitrosonaphthols - (VI). The preparation and properties of some cobalt (III) complexes. $J$. Nucl Inorg. Chem. 37: 51-54.

Belal, F. (1984). Spectrophotometic Determination of Halgenated $8-$ Hydrozyquinoline derivatives. Talanta 31 (8): 648-650.

Bellamy, L. J. (1966). The infrared spectra of Complex Molecules, Methluen, London $\mathrm{P}$ 306.

Corsini, A. and Louch, W. J. (1974). Proton Magnetic Resonance Studies of 8 - hydroxyquinoline derivatives Talanta 21: 252-252.

Eldawy, M. A and Elshabouri, S. R. (1975). Selective and Senstive Spectrophotometric Determination of Iron (II) with 7-Nitroso-8- quinolinol -5-sodium sulfonate. Anal. Chem 47 (11): 1844-1846.

Eugene, R. and Belford, R. L. (1964). Spectroscopy and Photometry of Uranyl_Compounds Pergamon, Oxford, p 22.

James, A. M and Prichard, E. E (1974). Practical Physical Chemistry. 3 Ed. Longmans. London p 85. 
Morrison, R. T and Boyd, R. N. (1980). Organic Chemistry, $3^{\text {rd }}$ Edition Allyn and Bacon, Inc. new York, Boston, p 105.

Osmo, M. and Niemi, R. (1972). Oxine and its derivatives. Mikrochim. Acta p 728-30.

Rollins, O. W. and Oldham, M. M. (1971). Spectrophotometic Determination and Spectrophotometric Titration of Palladium. Anal Chem. 43 (2): 262 - 264.

Stary, J. (1964). The Solvent Extraction of Metal Chelates. Peramon, Oxford, p 80.

Sugii, A and Ogawa, N (1979). Preparation and properties of a chelating resin containing the nitroso resorcinol group. Talanta 26: 970973.
Takashi, K. Motomizu, S and Toei, K. (1973). The Solvent Extraction of the Ternary Complexes of Iron (II)- Rhodamine B. with various nitroso phenols. Anal Chim Acta 65:335-346.

Toei, K. and Motomizu, S. (1976). Properties and uses of the colorimetric reagents of 2- Ntroso - 5 diethylaminophenol and 2 - Nitroso -5diethylamino phenol for cobalt Analyst 101: 497 - 500 . 